every year the meat inspectors have failed to discover a single case of tuberculosis. This appears to me sufticient reason in itself for advocating the goat as a source of milksupply as compared with the cow without recording others. It is surprising also that there should be any hesitation in admitting the superiority of goats' milk over cows' milk as a food for infants. The casein of goats' milk forms a flocculent and much more digestible curd than that of the cow-a very important matter in the rearing of infants. The hard curd of cows' milk is responsible for a good deal of indigestion and diarrhcea of infants. I feel safe in stating that less evil results in this direction would occur by the consumption of goats' milk than with cows' milk. The nourishment obtained from goats' milk is also superior to that of cows' milk and is more suitable for infants.

The difficulty so far as Great Britain is concerned at present is that of obtaining goats' milk when required. But this is leasily obviated by importation. Milch goats are a familiar feature of the livestock industry of Europe; they are especially prominent in Switzerland, Italy, Germany, France, Spain, Malta, Egypt, Russia, and Norway. They are by their habits of life peculiarly adapted to the needs and surroundings of the peasantry or poorer classes of these countries. There is indeed nothing truer or apter than the homely saying that "the goat is the poor man's cow." This is so because milk, which is food and drink to all mankind, is furnished by the goat in its cheapest form, because its quality is superior to cow's milk for all purposes, and also because the proportionate yield is much greater than that of a cow. It is frequently said that the food required for one milch cow is sufficient for eight milch goats. It is to be remembered that the weeds, twigs, and waste vegetables will with the addition of only a small amount of hay and grain keep a goat or two. Cows must have a regular meal of a particular menu. It is more than probable that miners in coal districts would find in the goat a profitable friend and there is no reason why suburbia should not consider this question also. Dettweiler says: "It furnishes to its owner without doubt the best milk for nourishing infants, for the household, for the cooking of food and for coffee, besides butter and cheese." It is recommended that if one purposes to use goats' milk two goats should be employed, one of which should become "fresh" in the spring and the other in the autumn. Hilpert states "that it serves as a means of preserving health; witness the cures with goats milk in the mountain sanatoria especially from pulmonary disease." Dettweiler says : "Goats' milk most nearly resembles woman's milk, and on account of the ease with which it is digested is attended with happy results in the case of feeding of the sick and infants." Hoffman says: "Goats' milk more nearly resembles mother's milk than cows' when it comes to infant feeding." $\mathrm{He}$ also states that in Germany many children take the milk direct from the udder "as the kid does and thus escaped any chance of milk infection." Groats are good mothers and readily adopt infants, calves, and lambs. The use of goats' milk for suckling infants is familiar enough. Goats conceive a liking for the life which they nourish, since they conduct themselves with extraordinarily ready willingness to the one who takes their milk in the matter of gratifying the whims of a suckling or of the person who milks them.

In the analyses of human, cows', and goats' milk it will be noted that in the matter of albumin and casein human milk falls short of the goat's and the goat's shows a considerable lower percentage than the cow's. Goats' milk therefore more closely approximates to human milk than cows' milk in this respect and for the same reason the curd is less heavy, more flocculent, and more easily digested. Dr. O. G. Place, whose fields of observation have been New York, London, and Paris among the larger cities, and many of the cities in Italy, Arabia, China, and Japan, says: "Anyone who will take the trouble to look up the data will readily see that in those countries where the goat is domesticated and its milk is used in the family there is very little tuberculosis, almost no scrofulous glands, and the infant mortality naturally is decidedly less for these children who use the milk."

Italy is a country noted for its insanitary condition, and yet we find the infantile mortality 66 per cent. less than in our own country, and here too tuberculosis is seldom found. Italy is decidedly a goat country and there the feeding bottle is scarcely heard of. It is not an uncommon sight there to see an infant or small child drawing its dinner straight from the little goat which has been bronght on to the steps or into the house for the purpose. In
Norway we get the low death-rate of 44 per 1000. Here the wet nurse is employed in the absence of the mother and if neither is available the infant is fed direct from the little bowl into which the goat is milked. Feeding bottles are unknown in the country. A goat which gives less than a quart a day is not considered a milch animal. If it yields two quarts it is a good animal. In Furopean countries the goats which yield from three to five quarts a day are very numerous and the period of lactation is a very long one. It is stated that many goats yield from 10 to 18 times their body weight annually. Zurn says: "Very good goats can produce 4-5 litres (approximately quarts) for each kllogram ( $2 \frac{1}{5}$ pounds) of body weight, or at the least estimate double what a good milk cow can show for each kilogram of her weight." Many goats give milk for eight to ten months in the year.

Regarding the alleged odour of goats' milk, this is erroneous. If the goat is allowed to roam about and to eat weeds, twigs, and all kinds of vegetation at will the milk is apt to be very strong in odour. On the contrary, how. ever, if the animal is fed purposely for obtaining palatable milk no odour can possibly be detected. Hook says : "The mill from goats fed on an English meadow or roadside has no flavour to distinguish it from cons " milk."

I had purposed going into the feeding, breeding, and housing of goats but I will reserve that for a future communication. The above, $I$ think, is quite sufficient in itself to form a plea for the goat, and it is to be hoped that local authorities will see the advisability of adopting this animal as a means towards the reduction of the excessive infantile mortality which forms a feature of this country.

Glasgow.

\section{A CASE OF ACTINOMYCOSIS OF THE CHEEK CURED BY IODIDE OF POTASSIUM,}

WITH SUGGESTIONS AS TO THE POSSIBLE MEANS OF INFECTION AND SPREAD OF THE DISEASE.

BY ROBERT KNOX, M.D. EDIN., M.R.C.S. ENG., L.R.C.P. LOND.

THE importance of an early diagnosis in actinomycosis cannot be over-estimated. Thereby prompt treatment is ensured and in the majority of cases it leads to complete cure. The interest in the case recorded below lies in the early recognition of the disease and the complete cure of the patient in a few months by the free administration of iodide of potassium.

The patient, a girl, aged seven and a half years, was first seen on Sept. 11th, 1905. The abscess of the cheek had been first observed by the child's parents early in August. The patient was a well-nourished child and presented on examination a small irregular nodular swelling on the right cheek midway between the upper and lower jaws. The appearance of the swelling is worthy of note because it is by observing points of difference between this and other abscesses connected with faulty teeth that suspicion may first arise as to the true nature of the disease. The tumour was of about the size of a small walnut and was irregular in outline; small areas of softening could be detected on palpation and semi-fluctuation could be elicited on carefully palpating the swelling with one finger in the mouth and the other on the cheek. At these points the cutaneous surface was greatly thinned out and presented a bluish-red colour. When first seen there were several places on the surface where the inclosed pus tended to point and a thin crust was already forming over these points. On carefully examining the buccal mucous membrane several small abrasions could be detected and it was obvious that it was at this point that the infection had taken place. These abrasions had been caused by two lower molars which were in a state of advanced decay and had very rough edges. The patient presented constitutional symptoms which are usually found in cases of this disease as in other diseases associated with suppurative changes. The pulse was rapid, 140 per minute, and the evening temperature rose to about $101^{\circ} \mathrm{F}$. The child had lost weight, was very lethargic in her movements, and complained of feeling tired.

Suspecting the nature of the disease, I opened the abscess and the typical granules were seen in large quantities. One of these was teased out in water and showed on microscopic 
examination the mycelium of the fungus. It is worthy of note that the organism can be recognised without any staining. A specimen was forwarded to Dr. Kastes who confirmed the diagnosis. The faulty teeth were removed and the mouth was kept clean by using a mouth-wash of boraldehyde. The swelling on the cheek was treated with boric fomentations. The patient was given iodide of potassium in increasing doses until a maximum of 45 grains per diem was reached. A month later the following notes were made: "Swelling somewhat smaller, discharge ceased. Temperature $99 \cdot 6^{\circ}$, pulse 132 . Weight stationary." The child continued to improve and when last seen, ten months after the commencement of treatment, she was in good health and the swelling had disappeared leaving a firm cicatrix with very slight disfigurement.

The interesting points of this case are-(1) the early diagnosis of the disease; (2) the great value of iodide of potassium in the treatment; and (3) the direct evidence of infection through the faulty teeth. The importance of diagnosing this disease in its earliest stages cannot be overestimated. The existing literature on actinomycosis is almost invariably a record of the later stages of the disease and the results are frequently bad. The point I would wish to insist on would be the systematic examination of discharges from any doubtful case, particularly when the lesion occurs in the vicinity of the mouth and teeth. Many cases may be overlooked until the later and graver lesions become evident.

Great differences of opinion exist as to the value of iodide of potassium in the treatment of actinomycosis. The important point is to use the drug at a time when there is a chance of eradicating the disease. Cases in the advanced stages of the disease may be benefited by its use, but the possibility of a cure is an extremely remote one. Whether the simple treatment of opening the abscess and draining it would be sufficient for a cure it is impossible to say, but in this case the fact remains that the patient did not begin to improve until she was thoroughly under the influence of the drug. The action of the iodide in this disease is unknown ; possibly by promoting absorption of inflammatory products as they are formed it may check the spread of the disease. So far as I know, it can have no specific action on the organism of actinomycosis. Iodides are largely used in the treatment of this disease in veterinary practice and many cures have resulted. The evidence in the above case strongly points to infection of the tissues by way of the faulty teeth. The question then arises, How is the parasite conveyed to the patient? The generally accepted theory is that the parasite is carried on straw or grain to the subject in one of many wars, and without doubt cases are on record where this has been so, but there are many cases where the method of infection remains a mystery. In two other cases which I have had under my care the teeth had been faulty and both patients had suffered from alveolar abscesses and glandular suppurations earlier in their lives. Cases are recorded where the disease has been communicated by direct inoculation from one individual to another. In another case I had, an extensive skin lesion arose late in the history by the opening of an abscess connected with the pleura, illustrating a feature of the disease which is noteworthynamely, the tendency of the disease to work from within outwards. This tendency was particularly noticeable in the case which forms the subject of this paper. The abscess pointed outwards and opened on the skin surface. Contrary to the usual method of treatment in abscesses about the mouth it was encouraged to open outwards, as the danger of infection of the alimentary canal was recognised if the discharge found its way into the mouth and stomach. The other possible method by which the disease can be spread is by the consumption of infected meat. There can be no doubt that such meat finds its way into the market and is consumed. Animals having this disease can be seen at any of the leading metropolitan markets and slaughter-houses almost daily. The practice prevails of condemning the affected parts of the animal and so far as it goes this is the proper thing to do, but it is possible for the smaller and presumably the more active centres of infection to be overlooked, and here may arise a possible danger to the community. In countries where the disease is more prevalent than in Great Britain it is customary to condemn the whole carcass of an affected animal. This seems to be the only method by which the danger of extending the disease to the human subject can be checked. The danger of infecting the human subject in this way must surely be a real one when it is considered necessary to take such radical measures in other countries. In animals, as in man, the macroscopic appearances of the infected tissues bear a close relationship to the lesions of tuberculosis and it is sometimes impossible to differentiate without an appeal to microscopic examination. Bearing this in mind it is very probable that the disease is more prevalent than is generally supposed.

The accepted method of infection-i.e., by grains and straw-cannot account for all cases. Some unsuspected and common source of infection must exist. This must be through the food-supply and, bearing in mind that such infected meat is consumed, is it not likely that such con. sumption may be an important factor in the spread of this disease?

Highgate, $\mathrm{N}$.

\section{THE SPA TREATMENT OF CARDIAC DILATATION.}

BY W. BLACK JONES, M.D., B.S. LOND., D.P.H., PHXSTCIAN TO THE LEANGAMMARCH WELLS SPA.

THE two following cases of cardiac dilatation illustrate the results obtained at Llangammarch Wells by the adoption of methods somewhat similar to the Nauheim treatment.

CASE 1.-A man, aged 50 years, gave a history of cardiac pain of three months' duration. He had always been healthy, had been an athlete, and also was a heavy smoker. He suffered from giddiness, palpitation, and sleeplessness, but there was no dyspncea. Upon examination the heart was found to be dilated, the apex beat being slightly outside the nipple line. The pulse was regular, the rate being 90 , and the tension was somewhat increased. The abdomen was distended with flatus and be was constipated. The treatment adopted consisted of the administration of a glass of barium mineral water three times a day, a course of graduated baths, one every other day, together with massage to the abdomen. He was also dieted and was directed to take moderate exercise in hill climbing. He soon began to improve, he slept better, and the diuretic action of the water was well marked. After a month's treatment there was a decided improvement in the condition of the heart, the dilatation being considerably diminished, the apex being now well inside the nipple line. He slept well, his digestion had improved, and he had lost all symptoms of discomfort in the region of the heart.

CASE 2. - The second case was that of a young man, aged 18 years, who had suffered from dyspncea and cardiac pain for about one and a half years, following upon an attack of inflnenza. The heart was found to be dilated, the apex being in the nipple line. He had formerly had some albumin in his urine, but none was found while he was at Llangammarch. He was treated in a similar manner to the patient in Case 1 with the exception that no massage was given. He rapidly improved and lost his dyspncea and pain and after three weeks it was found that the dilatation of the heart was much reduced, the apex being three-quarters of an inch inside the nipple line.

The favourable result of the above cases I attribute not only to the action of the mineral water but to the general spa treatment which has been indicated above.

Llangammarch Wells.

St. John Ambulance Brigade.-At a wellattended meeting of persons interested in ambulance work, held at Torquay on Oct. 16 h h, under the presidency of the mayor, it was unanimously resolved to form a division of the St. John Ambulance Brigade for the town, and Dr. T. Dunlop was appointed honorary surgeon.

UNIVERSITY OF LoNDON.-We have received from the authorities of the University of London 17 pamphlets called Calendar pamphlets which contain the information in the Calendar of the University published separately for the convenience of students. Two separate pamphlets are issued for internal and external students of each faculty. They may be obtained at the price of $1 s$. each except that containing regulations and examination papers for matriculation, of which the price is $6 d$. 